\title{
The role of parents in the perfectionistic tendencies of university music students
}

\begin{tabular}{|r|l|}
\hline Journal: & International Journal of Music Education \\
\hline Manuscript ID & IJME-RS-16-0064.R1 \\
\hline Manuscript Type: & Original Article \\
\hline Keywords: & $\begin{array}{l}\text { parental infuence, perfectionism, South African tertiary institutions, music } \\
\text { students }\end{array}$ \\
\hline & $\begin{array}{l}\text { Perfectionism is a complex multidimensional construct with positive and } \\
\text { negative outcomes. Research has identified that parents could influence } \\
\text { perfectionistic inclinations which may lead to increased levels of anxiety } \\
\text { and ultimately lead to maladaptive tendencies. The aim of the study is to } \\
\text { explore the role of parents in the experience of perfectionism in South } \\
\text { African university music students. A total of 93 BA (Music) and BMus music } \\
\text { students from four South African university music departments participated } \\
\text { in the quantitative study by completing the Frost Multidimensional }\end{array}$ \\
\begin{tabular}{|c|} 
Perfectionism Scale (FMPS). The data were analysed according to the \\
variables of academic institution, type of music degree, academic year of \\
study, gender, home language and main instrument. The results showed \\
significant differences in BA (Music) students who scored significantly \\
higher than the BMus students in dimensions parental expectations and \\
parental criticism, along with students from the African language group. \\
The study provides valuable insight into the perfectionistic trends of South \\
African undergraduate music students, with particular emphasis on the \\
parental dimensions of perfectionism.
\end{tabular} \\
\hline
\end{tabular}

SCHOLARONE

Manuscripts 


\title{
The role of parents in the perfectionistic tendencies of university music students
}

\begin{abstract}
Perfectionism is a complex multidimensional construct with positive and negative outcomes. Research has identified that parents could influence perfectionistic inclinations which may lead to increased levels of anxiety and ultimately lead to maladaptive tendencies. The aim of the study is to explore the role of parents in the experience of perfectionism in South African university music students. A total of 93 BA (Music) and BMus music students from four South African university music departments participated in the quantitative study by completing the Frost Multidimensional Perfectionism Scale (FMPS). The data were analysed according to the variables of academic institution, type of music degree, academic year of study, gender, home language and main instrument. The results showed significant differences in BA (Music) students who scored significantly higher than the BMus students in dimensions parental expectations and parental criticism, along with students from the African language group. The study provides valuable insight into the perfectionistic trends of South African undergraduate music students, with particular emphasis on the parental dimensions of perfectionism.
\end{abstract}

\section{Keywords}

Frost Multidimensional Perfectionism Scale (FMPS), music students, parental Influences, perfectionism, socially oriented perfectionism, South African tertiary Institutions, 


\section{Introduction}

Music students experience multiple demands in the academic environment at tertiary level which involves numerous psychological pressures which they are often not well equipped to handle. Paradoxically, the nature of music performance demands high levels of perfection with continuous attempts of constant discipline and exposure to criticism, from self and others (Dews \& Williams, 1989).

Perfectionism is a complex personality construct characterised by striving for excessively high standards of performance, being overly concerned with mistakes and flaws, and the need to have extreme personal control (Bourne, 1995; Frost, Marten, Lahart, \& Rosenblate, 1990; Hewitt \& Flett, 1991a). For music students, setting high standards and striving for perfection may have positive consequences and increase motivation and achievement (Wristen, 2013), however, being overly critical places students at risk for decreased wellbeing, feeling stressed and result in depression (Dunkley, Blanstein, Masheb, \& Grilo, 2006; Hunt \& Eisenberg, 2010). Consequently, both positive and negative dimensions of perfectionism, known as perfectionistic strivings and perfectionistic concerns, should be taken into account when investigating this phenomenon.

Perfectionistic strivings was found to be associated with positive characteristics such as conscientiousness, endurance and positive attitude (Stoeber \& Otto, 2006; Stoeber \& Rambow, 2007). Moreover, it was found to be related to academic achievement in college students (Bieling, Israeli, Smith \& Anthony, 2003). In contrast, perfectionstic concerns is seen as the negative or maladaptive dimension of perfectionism and represents harsh negative attitudes toward mistakes, self-criticism, and unrealistically high expectations of self and others, often resulting is low self-esteem, anxiety and depression (Bourne, 1995; Hamachek, 1978; Stoeber \& Otto, 2006). 
It is important to consider the role of extrinsic and intrinsic motivation in perfectionism, especially when differentiating between perfectionistic strivings and perfectionistic concerns. Various studies have investigated how perfectionism relates to intrinsic and extrinsic motivation (McArdle \& Duda, 2004, Mills \& Blankenstein, 2000). The core findings show that self-oriented perfectionism associated with perfectionistic strivings (adaptive perfectionism), is mostly related to intrinsic motivation, whereas socially prescribed perfectionism (a core component of perfectionistic concerns) shows stronger correlations with extrinsic motivation. Interestingly, the overwhelming majority of studies show that perfectionist strivings is positively associated with academic performance, however, the relationship between perfectionistic concerns is less clear, especially in the arts performance domain.

Some researchers believe that perfectionism has its origins within the family, and suggest parental influence and childhood development as the main sources of most perfectionistic tendencies (Craddock, Church \& Sands, 2009; Flett, Hewitt \& Singer, 1995; Kawamura, Frost \& Harmatz, 2002; Neumeister \& Finch, 2006). Other possible influences include environmental and societal factors (Flett, Hewitt, Oliver, \& Macdonald, 2002). Recent studies propose that parents' perfectionism, parental pressure and parenting style may contribute to the development of perfectionism (Stoeber \& Childs, 2011). Hamachek (1978) argues that a home environment of nonapproval or inconsistent approval and conditional positive approval fuels maladaptive perfectionism. Growing up with nonapproval or inconsistent approval would result in never knowing how to please ones parents; consequently perfectionistic tendencies develop in order to win parental approval. An individual living with conditional positive approval from parents will most likely develop perfectionistic tendencies in order to secure feelings of love and approval.

Perfectionism in musicians 
With regard to perfectionism in musicians, findings mostly confirm that perfectionism is related to debilitating anxiety in musicians, and focus on negative characteristics such as trait anxiety and performance anxiety (Kenny, Davis, \& Oates, 2004; Langendörfer, Hodapp, Kreutz, \& Bongard, 2006; Mor, Day, Flett, \& Hewitt,1995). It was found that self-oriented and socially prescribed perfectionism is significantly correlated with performance anxiety, resulting in maladaptive perfectionism.

Few studies have investigated perfectionism in tertiary music students. Stoeber and Eismann (2007) sought to investigate how the facets self-oriented and socially prescribed perfectionism is related to music students' intrinsic and extrinsic motivation, effort, achievement and levels of anxiety. The study aimed to understand how perceived parental pressure and teacher pressure contributed to distress in young musicians. Their research was driven by results from previous studies indicating that parents and music teachers could contribute to levels of distress in developing musicians (Davidson, Howe, Moore, \& Sloboda, 1996; Persson, 1995). Their results showed that perfectionism has both positive and negative implications. Negative reactions to imperfection were associated with external factors such as extrinsic motivation and performance anxiety, whereas the positive side of perfectionism was associated with intrinsic motivation, invested effort and achievement. Various studies have shown that parents do influence perfectionistic tendencies in university students (Chang, 2000; Frost et al., 1990; Vieth \& Trull, 1999). Moreover, Vieth and Trull (1999) found significant gender correlations between parents and perfectionism: female students' perfectionism was highly associated with their perfectionistic mothers, whereas male students correlated similarly with their fathers. This finding highlights the importance of same-sex modelling (mother-daughter, father-son) as opposed to opposite-sex modelling. 
It appears that there is still a paucity of research about contributing social factors in perfectionism in music students. The present article aims to focus on aspects of socially prescribed perfectionism, in particular the role of parents in the experience of perfectionism, in South African undergraduate music students. The results presented in the current article forms part of a larger study which focused on perfectionism, academic achievement and performance anxiety in undergraduate music students. Given that South African universities represent a culturally diverse population, the variables in this study included academic institution, degree type, year of study, gender, home language, and main instrument.

\section{Method}

Participants and procedure

The participants for this study were 93 undergraduate music students enrolled for either a BA (Music) or BMus degree. Music students from the University of Pretoria (UP), NorthWest University (NWU), University of the Free State (UFS) and Stellenbosch University (SU) took part. A purposeful sampling strategy was used. After receiving appropriate ethical clearance from each university, music students were invited to take part in the study. Those who volunteered to participate in the study were informed of the aim and ethical implications of the study. On completion of informed consent forms, questionnaires were completed in the presence of one of the researchers.

\section{Research instruments}

The survey included a section eliciting general information including academic institution, degree type, year of study, gender, home language and main instrument, and the Frost Multidimensional Perfectionism Scale (FMPS) by Frost, Marten, Lahart and Rosenblate 
(1990) which consists of 35 questions measuring the six dimensions of perfectionism. The subscales of the instrument included: concern over mistakes (CM); personal standards (PS); parental expectations (PE); parental criticism (PC); doubts about actions (DA) and organization (O). The responses were indicated on a five-point Likert scale, from 1 (strongly disagree) to 5 (strongly agree). The FMPS measures four types of self-oriented perfectionism (organization, personal standards, concern over mistakes, and doubts about actions) and two types of socially prescribed perfectionism (parental expectations and parental criticism).

Descriptive statistics and data analysis

Table 1 presents the descriptive statistics of the sample according to the variables.

Table 1: Descriptive statistics of the variables academic institution, course type, year of study, gender and home language

\begin{tabular}{|l|l|l|}
\hline & $\boldsymbol{n}=\mathbf{9 3}$ & $\%$ \\
\hline Academic institution: & & \\
North West University (NWU) & 32 & 34 \\
University of Pretoria (UP) & 24 & 26 \\
Stellenbosch University (SU) & 21 & 23 \\
University of the Free State (UFS) & 16 & 17 \\
\hline Course type: & & \\
BA(Music) & 34 & 37 \\
BMus & 59 & 63 \\
\hline Year of study: & 36 & 39 \\
First year & 25 & 27 \\
Second year & 32 & 34 \\
Third year & 34 & 37 \\
\hline Gender: & 59 & 63 \\
\hline Male & \\
Female & & \\
\hline
\end{tabular}




\begin{tabular}{|c|c|c|}
\hline \multicolumn{3}{|l|}{ Home Language: } \\
\hline English & 28 & 31 \\
\hline Afrikaans & 43 & 46 \\
\hline African & 21 & 23 \\
\hline Other ${ }^{3}$ & 8 & 9 \\
\hline \multicolumn{3}{|l|}{ Main instrument: } \\
\hline Keyboard (piano and organ) & 32 & 34 \\
\hline Vocal & 28 & 30 \\
\hline String (violin, viola, cello) & 17 & 18 \\
\hline Wind (woodwind and brass) & 14 & 15 \\
\hline Percussion $^{4}$ & 2 & 2 \\
\hline
\end{tabular}

The Mann-Whitney $U$ test was used to determine statistically significant differences between the music course and gender groups on the six dimensions of the FMPS. Similarly, the Kruskall-Wallis test was employed to determine significant differences between the various universities, years of study, language groups and instrument groups.

The FMPS measured high in reliability with the coefficients of internal consistency ranging from .77 to .93 (Table 2). This is in line with the overall reliability score of .90 obtained by Frost et al. (1990, 454-455) during the original scale development.

Table 2. Reliability scores of the Frost Multidimensional Perfectionism Scale

\begin{tabular}{|l|c|}
\hline Dimension of Perfectionism & $\begin{array}{c}\text { Cronbach's } \\
\text { Alpha }\end{array}$ \\
\hline Concern over Mistakes (CM) & .88 \\
\hline Personal Standards (PS) & .83 \\
\hline
\end{tabular}




\begin{tabular}{|l|c|}
\hline Parental Expectations (PE) & .84 \\
\hline Parental Criticism (PC) & .84 \\
\hline Doubts about Actions (DA) & .77 \\
\hline Organization (O) & .93 \\
\hline
\end{tabular}

\section{Results}

The results of the study aims to illuminate the social dimensions of perfectionism in undergraduate music students, specifically referring to the role of parents.

\section{Correlation between multidimensional aspects of perfectionism}

A look into the positive and negative experiences of perfectionism yielded interesting results, as the subscales of the FMPS correlated with one another on several levels (Table 3). The parental dimensions of perfectionism, parental expectations (PE) and parental criticism (PC) correlated strongly with one another $(r=0.584 ; p=0.000)$. Other correlations involving the parental dimensions of perfectionism include the moderate relation between concern over mistakes $(\mathrm{CM})$ and parental criticism $(r=0.453 ; p=0.000)$, and weak correlations between both $\mathrm{CM}$ and $\mathrm{PE}(r=0.241 ; p=0.20)$, and DA and PC $(r=0.289 ; p=0.005)$. The intercorrelations between the various dimensions emphasise the intricate nature of perfectionism. 
Table 3. FMPS: Spearmen's nonparametric correlations

\begin{tabular}{|c|c|c|c|c|c|c|}
\hline & $\begin{array}{l}\text { Concern over } \\
\text { Mistakes }\end{array}$ & $\begin{array}{l}\text { Personal } \\
\text { Standards }\end{array}$ & $\begin{array}{l}\text { Parental } \\
\text { Expectations }\end{array}$ & Parental Criticism & $\begin{array}{l}\text { Doubts about } \\
\text { Actions }\end{array}$ & Organization \\
\hline $\begin{array}{l}\text { Concern over } \\
\text { Mistakes }\end{array}$ & 1.000 & & & & & \\
\hline Personal Standards & $.462^{* *}$ & 1.000 & & & & \\
\hline Parental Criticism & $.453^{* *}$ & .176 & $.548^{* *}$ & 1.000 & & \\
\hline Doubts about Actions & $.441^{* *}$ & $.223^{*}$ & .157 & $.289^{* *}$ & 1.000 & \\
\hline Organization & -.085 & $.390^{* *}$ & .096 & -.047 & 5.058 & 1.000 \\
\hline
\end{tabular}

**. Correlation is significant at the 0.01 level (2-tailed).

*. Correlation is significant at the 0.05 level (2-tailed). 
Confounding variables. The variables academic institution, course type, year of study, gender, home language and main instrument within the sample were compared on all subscales of the questionnaire, and proved overall to be relatively consistent. Only a few statistical significant differences between the variables were evident.

Academic institution. In order to determine significant differences between the participants from the various universities, the Kruskall-Wallis test was employed. Significant differences $(p<.0 .05)$ were found on two dimensions: PE ( $p$.008), and PC ( $p$.028).

Figure 1 includes the overall scores of the dimensions of the FMPS across universities. Students from NWU (16.71) displayed significantly higher scores than SU (12.85) on the PE (parental expectations) subscale; whereas the PC (parental criticism) subscale of the NWU (11.93) was considerably higher than both SU (9.19) and the UFS (9.12). These differences were significant at the $1 \%$ and $5 \%$ levels. 


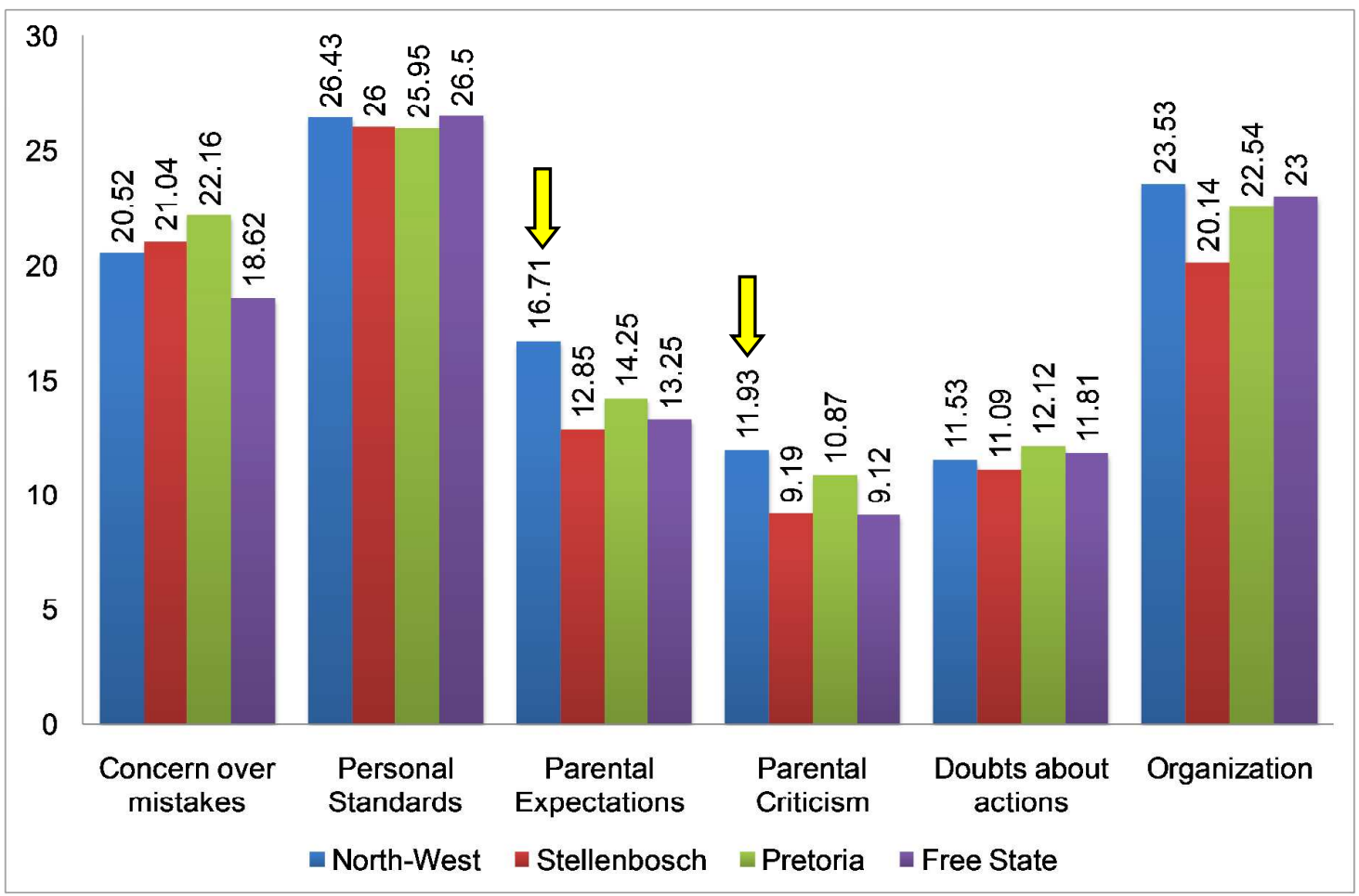

Figure 1. FMPS: Comparisons between universities

Course type. To explore any statistical differences between the participants from the BA (Music) and BMus degrees, the Mann-Whitney $U$ test was employed on all subscales of the questionnaire. The results suggest differences in perfectionistic tendencies, specifically PE $(p .007)$ and PC (p .005)

The FMPS delivered statistical significant differences on two of the subscales (Figure 2). The PE subscale of the FMPS presented significantly higher scores for the BA (Music) students (16.26) than the BMus students (11.82). Similarly, the PC subscale revealed higher scores for the BA (Music) participants (11.82) compared to the BMus participants (9.83). These differences were significant at the $1 \%$ level of significance. 


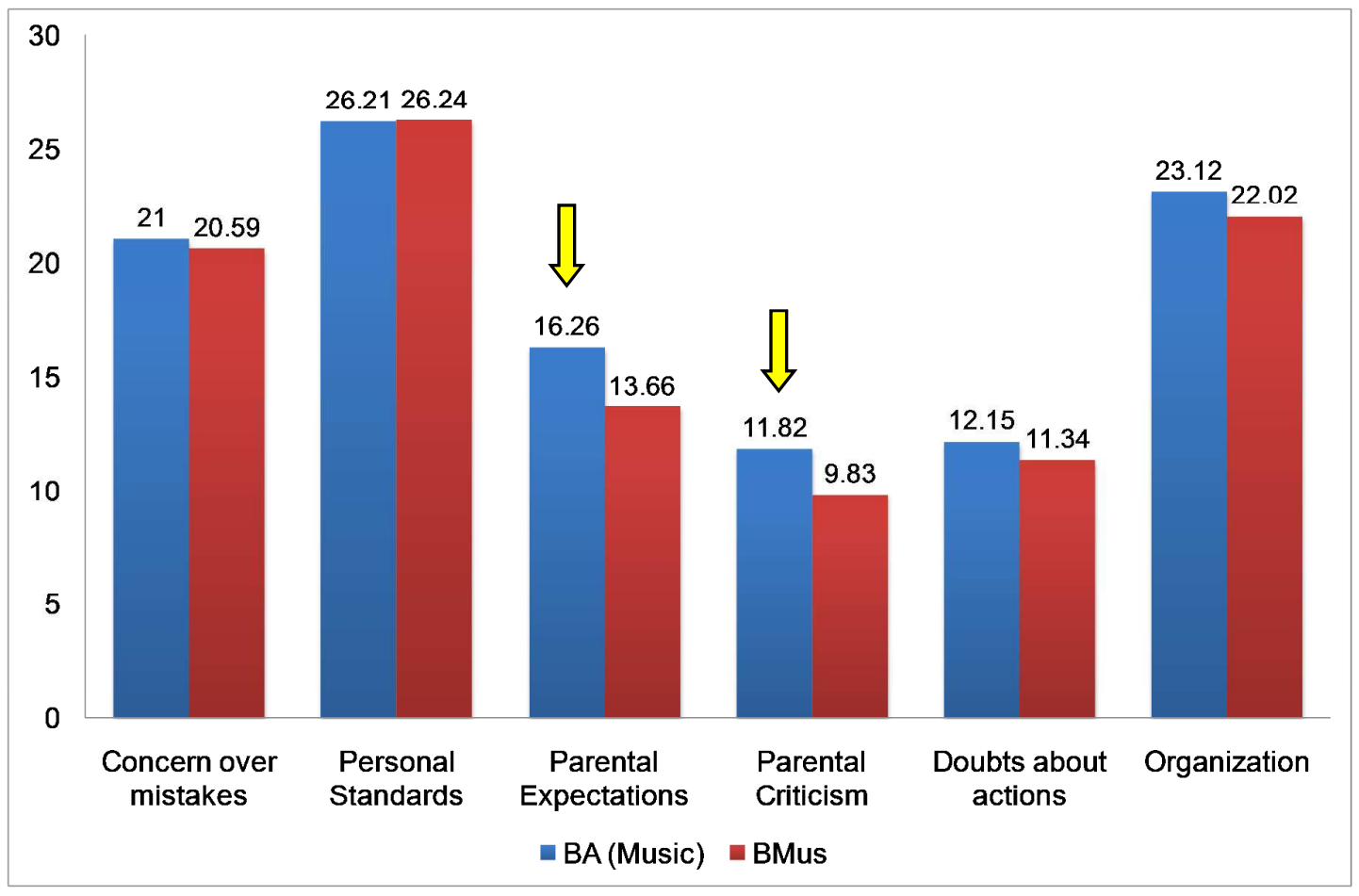

Figure 2. FMPS: Comparisons between BA (Music) and BMus degrees

Academic year of study. We were curious to find out if there were differences between the various years of study and whether parental influences had an impact over the years (Fig 3). This was considered by means of the Kruskall-Wallis test. The scores of the first, second and third year participants were fairly parallel on all the subscales, thereby implying the absence of any statistical significant differences within the sample. 


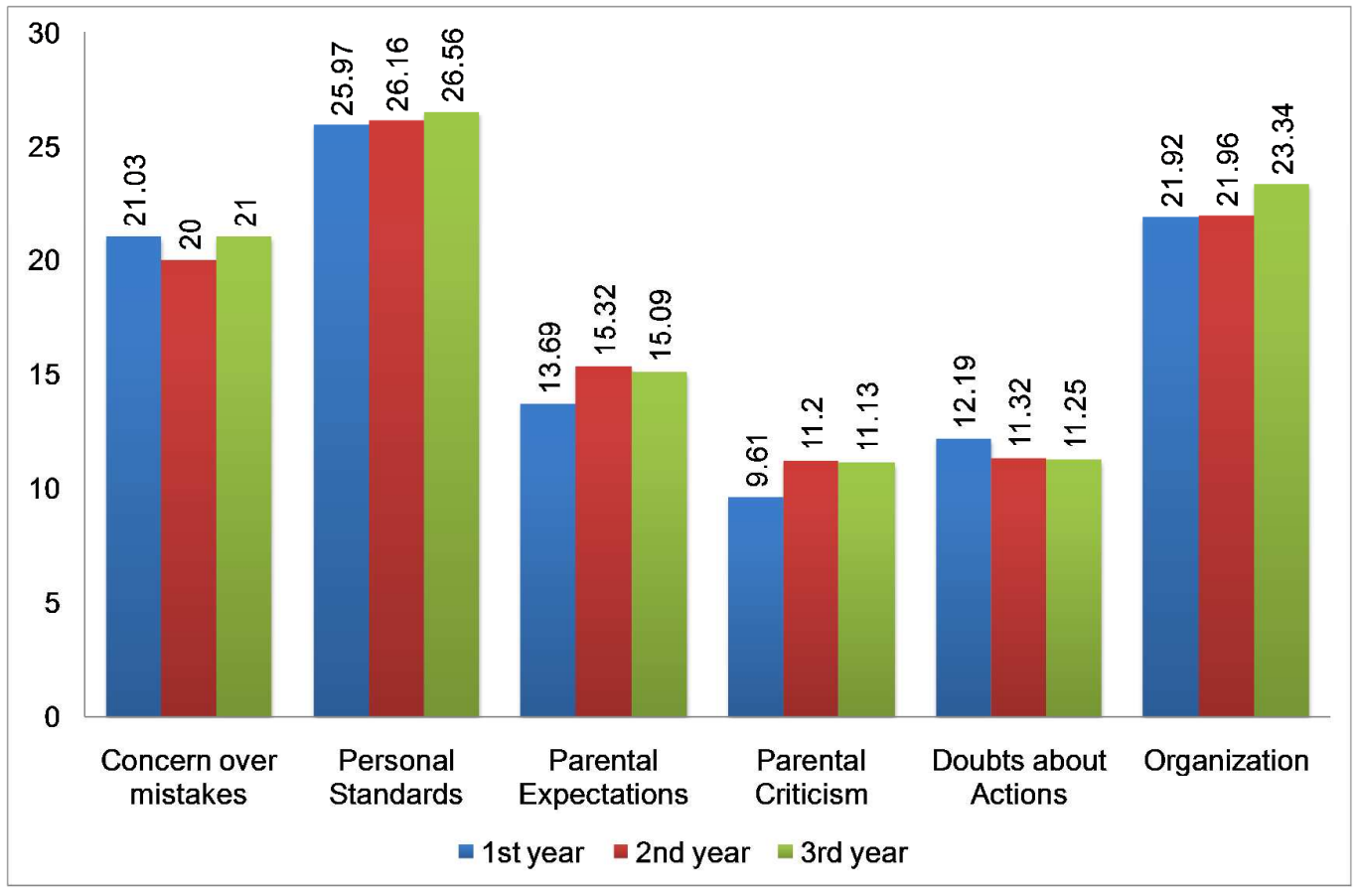

Figure 3. FMPS: Comparisons between academic years of study

Gender. Gender differences on the dimensions of the questionnaire were explored by means of the Mann-Whitney $U$ test. Surprisingly the results displayed no significant differences between the genders on any dimensions of perfectionism (Fig. 4). 


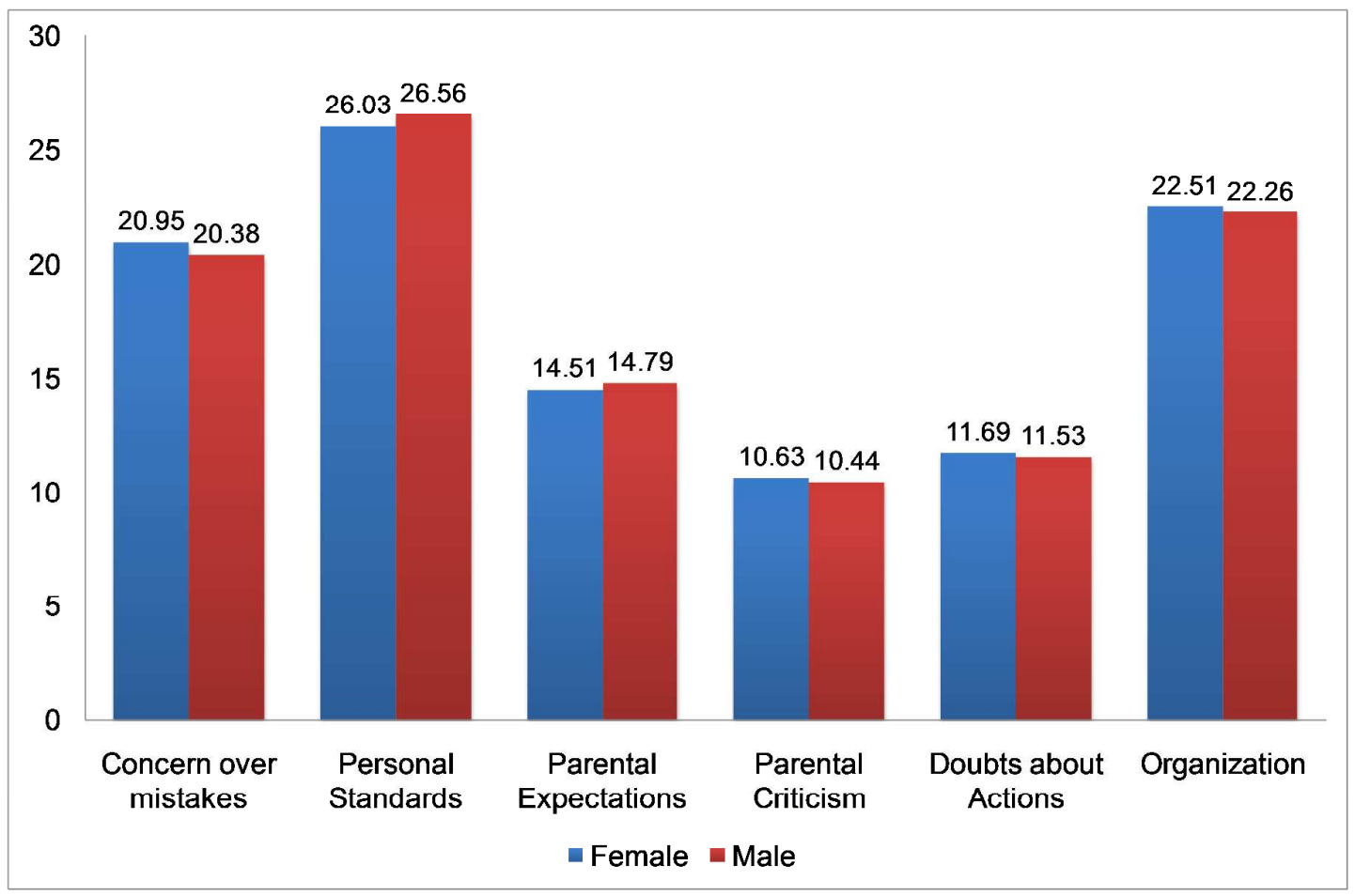

Figure 4. FMPS: Gender

Home language. The Kruskall-Wallis test was applied to all the subscales of the FMPS in order to compare the language groups and look for any significant differences. Significant differences were found on the PE ( $p$.001) and PC ( $p$.076) subscales.

The FMPS delivered statistical significant data on the PE and PC subscales. The students from the African language ${ }^{5}$ (17.67) group scored considerably higher than both the Afrikaans (13.37) and English (13.24) students on the PE subscale and significantly higher (11.86) than the English (9.29) students on the PC subscale. The differences are respectively at the $1 \%$ and $5 \%$ levels of significance as presented in Figure 5. 


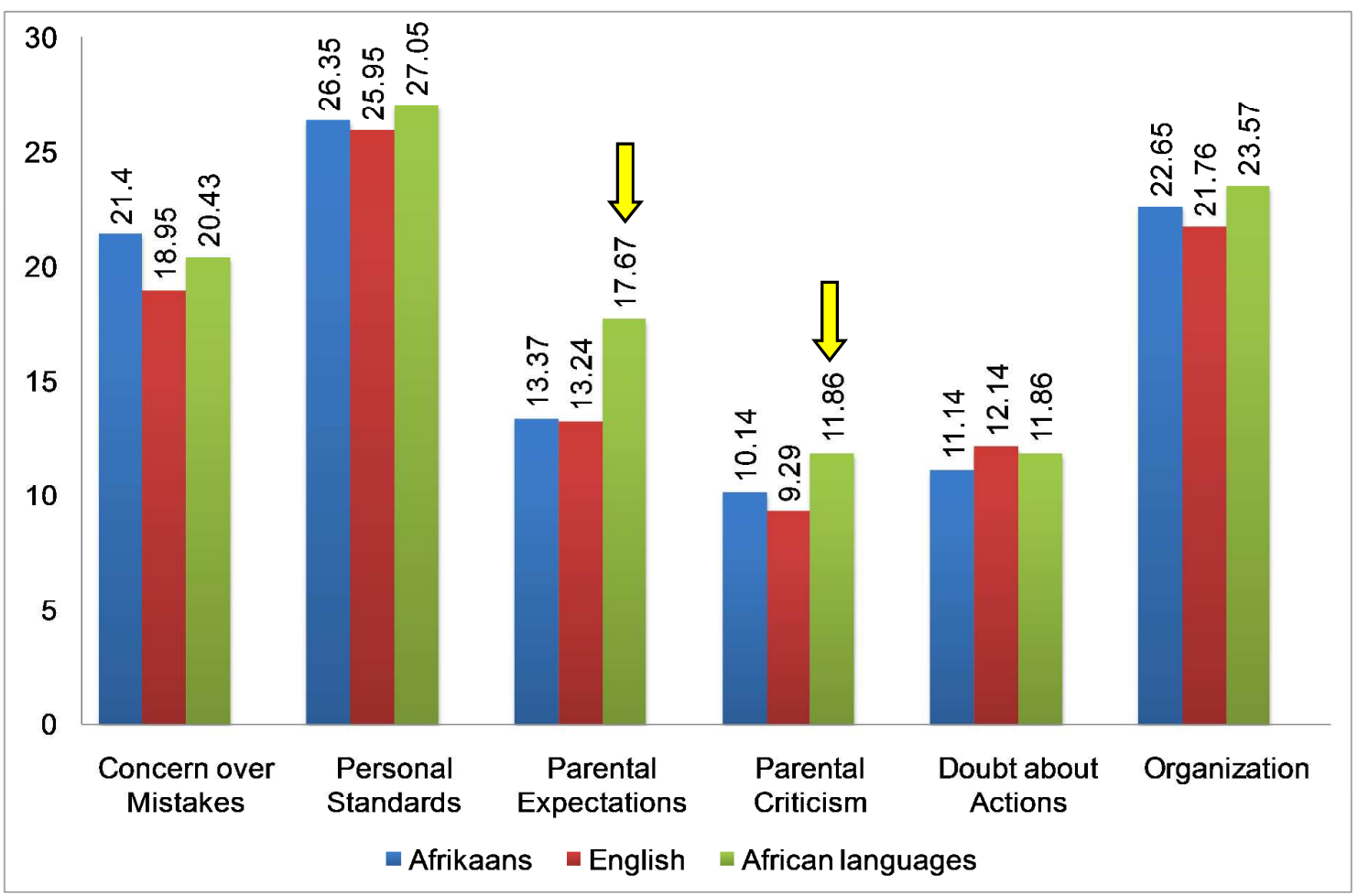

Figure 5. FMPS: Comparisons between language groups

Main music instrument. The main instruments groups were assessed by the KruskallWallis test and the scores on all the subscales of the questionnaire were taken into account. Results revealed significant difference - specifically on the PE ( $p .023)$ subscale.

The instrument groups scored similarly on most of the FMPS-subscales. The CM displayed a notable difference between the strings (23.35) and the winds (16.64), however, the scores of the keyboard (21.06) and voice (20.71) contributed to a more even distribution between the instrument groups - thereby leading to a statistical insignificant result. Similar observations can be made on the $O$ subscale between the keyboard (23.81) and winds (19.71). However, the PE subscale delivered noteworthy results as the voice (16.75) scored 
significantly higher than the winds (12.57). These differences, at the $5 \%$ level of significance, are displayed in Figure 6.

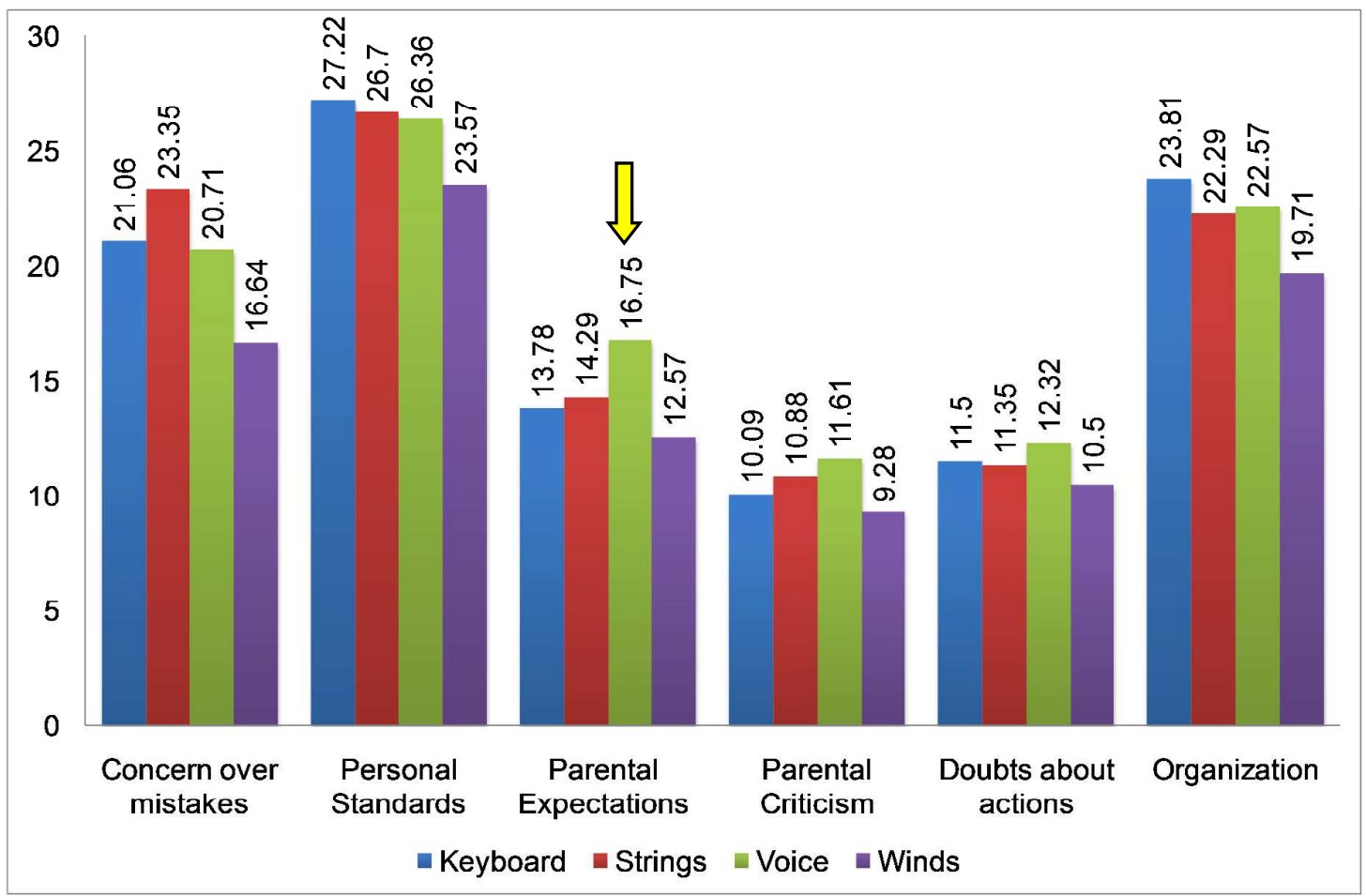

Figure 6. FMPS: Comparisons between main instrument groups

\section{Discussion}

Perfectionism is a complex construct consisting of various interacting components (Frost et al., 1990; Hewitt \& Flett 1991b). The current study focused on the social prescribed dimensions of perfectionism by considering the extent to which parents influence the perfectionistic tendencies in undergraduate music students.

The dimension concern over mistakes is generally regarded as one of the fundamental aspects of perfectionism, with elements of the self-critical and self-evaluative at its core. This 
"traditional" dimension of perfectionism correlated with both of the parental dimensions of perfectionism - displaying a moderate correlation with parental criticism and a weak relation with parental expectations. Furthermore, there were moderate correlations with the dimensions personal standards and doubts about actions. Concern over mistakes therefore has some mutual or shared aspects with each of these dimensions. These results are fairly comparable with what Frost et al. (1990) found, as the concern over mistakes similarly revealed moderate correlations with the personal standards, parental criticism, and doubts about actions dimensions. They likewise found a moderate association between concern over mistakes and parental expectations, but unlike the current study's weak relation, theirs displayed a moderate correlation.

The parental expectations dimension of perfectionism revealed a strong correlation with parental criticism and concern over mistakes. This implies that higher expectations from parents are also related to greater disapproval from them. This finding corresponds with Frost et al. (1990) who found a similar relation between parental expectations and parental criticism in one of their earliest studies. This correlation between expectations and criticism is in line the "parental pressure" hypothesis on the origins of perfectionism (Flett, et al., 2002; Stoeber \& Childs, 2011) which is rooted in social expectations and social reactions model. Therefore, a child perceives parental pressure to be perfect and criticism if they fail to meet expectations. In our study parental criticism however, revealed a weak correlation with doubts about actions. One can assume that feeling uncertain about one's abilities or performance could be associated with parental disapproval, or phrased differently, that parents tend to be more critical in situations where the individual displays insecurity regarding their own actions. The parenting style hypothesis on the origins of perfectionism can possibly account for this correlation (Stoeber \& Childs, 2011) in that psychologically controlling parenting style (authoritarian) is characterized by a "highly evaluative way of interacting" (Craddock, Church \& Sands, 2009, 137), in this case critical feedback. It 
appears that constant parental criticism can lead to and is related to increased levels of dysfunctional perfectionism (Soenens, Luyckx, Vansteenkiste, Lyuten, Duriez, \& Goossens, 2008), such as insecurity about one's abilities.

In comparing the students from the four universities, the group from the North-West University (NWU) displayed significantly higher levels on both the parental expectations and parental criticism dimensions of perfectionism. At first we assumed that an explanation for this finding could be that the results showed a culturally strong Afrikaans tradition within the university, and the values of the Afrikaans community. Traditionally the Afrikaans parenting style tends to be autocratic in the sense that parents are often involved in prominent decisions regarding their children's future. However, our assumption of this result was challenged when the data was analysed further, and a different outcome unfolded.

In comparing parental influences of perfectionism between the two music degrees we found stark and surprising differences between them. Firstly, the BA (Music) students scored higher than BMus students on both dimensions, parental criticism and parental expectations. This was interesting in the sense that the BA (Music) degree is a three year degree as opposed to the four year BMus degree. The BA (Music) degree could therefore be perceived to have a less demanding academic and musical performance requirement compared to the performance pressure some final year BMus students endure. One would also expect that students enrolled for the BMus degree would experience greater pressure from their parents given that it is a four year degree program. This led to the supposition that other factors, beyond the academic requirements of the degree, are at play.

Further analysis of the home language groups provided some clarity on previous findings which showed significant differences between the parental dimensions of perfectionism. The students from the African language group scored significantly higher on the parental expectations and parental criticism dimensions than the other language groups. This finding 
suggests that cultural values could play a significant role and contribute to the perception of parental involvement in tertiary studies (De Carvalho, 2001; Perna \& Titus, 2005;

Theodorou, 2007).

Incidentally, the majority of the participants from the African language group are enrolled for BA (Music) and study at the NWU. ${ }^{6}$ It is highly probable therefore; that the increased levels of parental criticism and parental expectations are possibly characteristic of a specific geographical group of participants. It is also possible that the curriculum content of the BA degree varies significantly between universities and that this finding is indicative of the pressure the students experience to meet the difficulty and expected required musical performance skills of the BA (Music) degree at NWU. A further explanation could be that this population of the BA (Music) student at NWU is representative of first generation tertiary studies. Understandably the stakes are high and there is immense pressure on the student to perform and not disappoint their parents, who were not granted the opportunity for further study. Castro and Rice (2003) investigated perfectionism and ethnicity and its correlation between depression and academic achievement in a mixed American college population. They found that perfectionism was significantly higher among the minority groups, especially between dimensions such as concern about mistakes, criticism from parents, and self-doubt. It is therefore possible that broadly speaking our finding also reflects the phenomenon of experiences of minority ethnic groups. However, further research is necessary to support our suppositions.

The comparison between the different instrument groups revealed one important difference, specifically on the parental expectations dimension of perfectionism. The voice students scored significantly higher than the winds. Again, it is interesting to note that the majority of the African language students indicated voice as their main instrument, and most are 
enrolled for a BA (Music) degree at NWU. ${ }^{6}$ Again, this finding supports our hunch that result reflects a particular situation at NWU.

The academic year of study and gender variables delivered no differences on the measurements of perfectionism. Even though perfectionism is considered more typical of girls than boys (Baker, 1996; Bellamy, 1993; Rimm, 2007) this finding is not supported in adults. The fact that there were no gender differences evident in the data concurs with general research that cannot confirm differences between perfectionism in males and females. This finding however, also needs further exploration with a larger sample.

Overall our findings suggest that parents play a significant role in the perfectionistic tendencies of the music student within a tertiary academic context. Parental contributions to perfectionism also revealed important differences between the students from the various universities, music degrees, home language and music instrument groups.

\section{Limitations and Recommendations}

Our study included music departments from four major universities in South Africa. This is by no means representative of all undergraduate music students. We acknowledge that our findings could include more data from other major universities for more accurate representation of South African music students. Although the current study did not yield any variances between the academic year of study, nor gender in terms of parental influences of perfectionism, it would be interesting to determine whether maladaptive perfectionism tendencies has changed since high school - a period generally characterised by higher parental involvement. There is a definite need for longitudinal research investigating the development of perfectionism, parental influences on academic behaviour and music performance anxiety. 
Several methodological limitations were identified during the course of the study. Although the FMPS instrument confirms the multidimensional nature of perfectionism, the quantitative research design is limiting in the sense that it merely reveals significant correlations between dimensions of perfectionism but does not provide clarity on the dynamic and complex nature of the construct. A mixed method design would yield a more nuanced understanding of the developmental nature and differential relationship between parents and perfectionism in music students.

The current sample delivered interesting differences between the socio-demographic variables which can possibly lead to significant discoveries in future research. The influence of parents in tertiary music studies is an important aspect that emerged from the literature and furthermore displayed significant differences across several of the variables within the sample - including the academic institution, the degree type, home language and main music instrument. Additional research, specifically of a qualitative nature, could explore the role of parenting styles, attachment styles and parents' achievement orientations, in addition to socio-cultural and environmental factors contributing to perceived parental influences related to perfectionism.

\section{Conclusions}

This study, the first of its kind in South Africa to empirically investigate parental influences on perfectionism in undergraduate music students. It showed that parents do play a significant role in maladaptive perfectionistic tendencies in this population. Similar to other studies on perfectionism, the findings provides evidence that perfectionism is a complex phenomenon with multiple relations that are not easily generalised. Overall, the study revealed that the parental factors, were found to have the most significant impact on BA (Music) students, specifically voice as main instrument. The results of this study highlight interesting sociodemographic variabilities that deserve further scrutiny. There was no significant difference in 
academic year of study and gender. The results confirm that parents do have a significant impact on socially prescribed perfectionism in undergraduate South African music students. Additional research is necessary to understand the complexities of the phenomenon and its affect on the well-being and success of music student.

\section{Notes}

${ }^{1}$ It is important to mention that data discussed here are part of the findings of a larger study which investigated self-oriented and social-oriented perfectionism and correlations with academic motivation and performance anxiety in South African music students.

${ }^{2}$ Only the results of the subscales concern over mistakes, parental expectations and parental criticism will be discussed in this article. The other subscales will be elaborated on in a subsequent article.

${ }^{3}$ The Other language group was omitted from the comparative analytic tests due to its limited sample size. A larger sample would be necessary in order to substantiate any claims.

${ }^{4}$ The percussion instrument group was omitted from the comparative analysis tests due to its limited sample size.

${ }^{5}$ The participants clustered under the African language group included the following languages: IsiXhosa, Sepedi, Sesotho, Setswana, Shona, and Zulu.

${ }^{6}$ Of the 21 African language participants, 17 (81\%) attended NWU. Furthermore, $13(62 \%)$ of these students were enrolled for the BA (Music) degree and specifically indicated voice as their first instrument.

\section{References}

Baker, J.A. (1996). Everyday stressors of academically gifted adolescents. Journal of Secondary Gifted Education, 7, 356-368. 
Bellamy, J. (1993). Perfectionism in adolescents: A comparison of private and public school students.

Unpublished master's thesis. University of Manitoba, Canada.

Bieling, P.J., Israeli, A., Smith, J., \& Antony, M.M. (2003). Making the grade: The behavioural consequences of perfectionism in the classroom. Personality and Individual Differences, 35, 163-178.

Bourne, E. (1995). The anxiety and phobia workbook. Oakland, CA: New Harbinger.

Castro, J. R. \& Rice, K. G. (2003). Perfectionism and ethnicity: Implications for depressive symptoms and selfreported academic achievement. Cultural Diversity and Ethnic Minority Psychology 9(1),64-78.

Chang, E. C. (2000). Perfectionism as a predictor of positive and negative psychological outcomes: Examining a mediation model in younger and older adults. Journal of Counseling Psychology 47,18-26.

Craddock, A.E., Church, W. \& Sands, A. (2009). Family of origin characteristics as predictors of perfectionism. Australian Journal of Psychology, 61(3),136-144.

Davidson, J.W., Howe, M.J.A., Moore, D.G., \& Sloboda, J.A. (1996). The role of parental influences $n$ the development of musical performance. British, Journal of Developmental Psychology, 14, 399-412.

De Carvalho, M.E. (2001). Rethinking family-school relations: A critique of parental involvement in schooling. London: Lawrence Erlbaum.

Dews, C.L.B., \& Williams, M.S. (1989). Student musicians' personality styles, stresses and coping patterns. Psychology of Music, 17(1),37-47.

Dunkley, D.M., Blankstein, K.R., Masheb, R.M., \& Grilo, C.M. (2006). Personal standards and evaluative concerns dimensions of "clinical" perfectionism: a reply to Shafran et al. (2002, 2003) and Hewitt et al. (2003). Behaviour, Research and Therapy, 44, 63-84.

Flett, G. L., Hewitt, P.L., \& Singer, A. (1995). Perfectionism and parental authority styles. Individual Psychology: Journal of Adlerian Theory, Research and Practice, 51(1),50-60.

Flett, G.L., Hewitt, P.L., Oliver, J.M., \& Macdonald, S. (2002). Perfectionism in children and their parents: A developmental analysis. In G.L. Flett, \& P.L. Hewitt (Ed.), Perfection, (pp. 89-132). Washington, DC: American Psychological Association.

Frost, R.O., Marten, P., Lahart, C., \& Rosenblate, R. (1990). The dimensions of perfectionism. Cognitive Therapy and Research 14,449-468. 
Hamachek, D.E. (1978). Psychodynamics of normal and neurotic perfectionism. Psychology: A Journal of Human Behaviour, 15,27-33.

Hewitt, P.L., \& Flett, G.L. (1991)a. Dimensions of perfectionism in unipolar depression. Journal of Abnormal Psychology, 100,98-101.

Hewitt, P.L., \& Flett, G.L. (1991)b. Perfectionism in the self and social contexts: Conceptualization, assessment, and association with psychopathology. Journal of Personality and Social Psychology, 60,456-470.

Hunt, J.H., \& Eisenberg, D. (2010). Mental health problems and help-seeking behaviour among college students. Journal of Adolescent Health, 46,3-10.

Kawamura, K.Y., Frost, R.O. \& Harmatz, M.G. (2002). The relationship of perceived parenting styles to perfectionism. Personality and Individual Differences, 32,317-327.

Kenny, D.T., Davis, P.T., \& Oates, J. (2004). Music performance anxiety and occupational stress amongst opera chorus artists and their relationship with state and trait anxiety and perfectionism. Journal of Anxiety Disorders 18,757-777.

Langendörfer, F., Hodapp, V., Kreutz, G., \& Bongard, S. (2006). Personality and performance anxiety among professional orchestra musicians. Journal of Individual Differences, 27(3),162-171.

McArdle, S,m \& Duda, J.L. (2004). Exploring social-contextual corelates of perfectionism in adolescents: A multivariate perspective. Cognitive Therapy and Research, 28(6), 765-788.

Miller-Day, M., \& Marks, J.D. (2006). Perceptions of parental communication orientation, perfectionism, and disordered eating. Health Communication, 19,153-163.

Mor, S., Day, H.I., Flett, G.L., \& Hewitt, P.L. (1995). Perfectionism, control, and components of performance anxiety in professional artists. Cognitive Therapy and Research, 19,207-225.

Neumeister, K. L. S. \& Finch, H. (2006). Perfectionism in high-ability students: Relational precursors and influences on achievement motivation. Gifted Child Quarterly, 50(3),238-251.

Perna, L.W., \& Titus, M.A. (2005). The relationship between parental involvement as social capital and college enrollment: An examination of racial/ethnic group differences. Journal of Higher Education, 76(5),485-518.

Personn, R.S. (1995). Psychosocial stressors among student musicians: A naturalistic study of the teacherstudent relationship. International Journal of Arts Medicine, 4, 7-13. 
Rimm, S. (2007). What's wrong with perfect? Clinical perspectives on perfectionism and underachievement. Gifted Education International, 23,246-253.

Soenens, B., Luyckx, K., Vansteenkiste, M., Lyuten, P., Duriez, B., \& Goossens, L. (2008). Maladaptive perfectionism as an intervening variable between psychological control and adolescent depressive symptoms: A three-wave longitudinal study. Journal of Family Psychology, 22(3),465-474.

Stoeber, J., \& Eismann, U. (2007). Perfectionism in young musicians: Relations with motivation, effort, achievement, and distress. Personality and Individual Differences, 43(8),2182-2192.

Stoeber, J., \& Otto, K. (2006). Positive perfectionism: Conceptions, evidence, challenges. Personality and Social Psychology Review, 10,219-319.

Stoeber, J., \& Rambow, A. (2007). Perfectionism in adolescent school students: Relations with motiation, achievement, and well-being. Personality and Individual Differences, 42,1379-1389.

Theodorou, E. (2007). Reading between the lines: Exploring the assumptions and implications of parental involvement. International Journal about Parents in Education, 1,90-96.

Vieth, A.Z., \& Trull, T.J. (1999). Family patterns of perfectionism: An examination of college students and their parents. Journal of Personality Assessment, 72,49-67.

Wristen, B.G. (2013). Depression and anxiety in university music students. National Association for Music Education, 31(2),20-27. 